\title{
Overpressure Contact Printing
}

\author{
Qijie Guo, Xiaowei Teng, and Hong Yang*
}

Department of Chemical Engineering and Laboratory for Laser Energetics, 206 Gavett Hall, University of Rochester, Rochester, New York 14627-0166
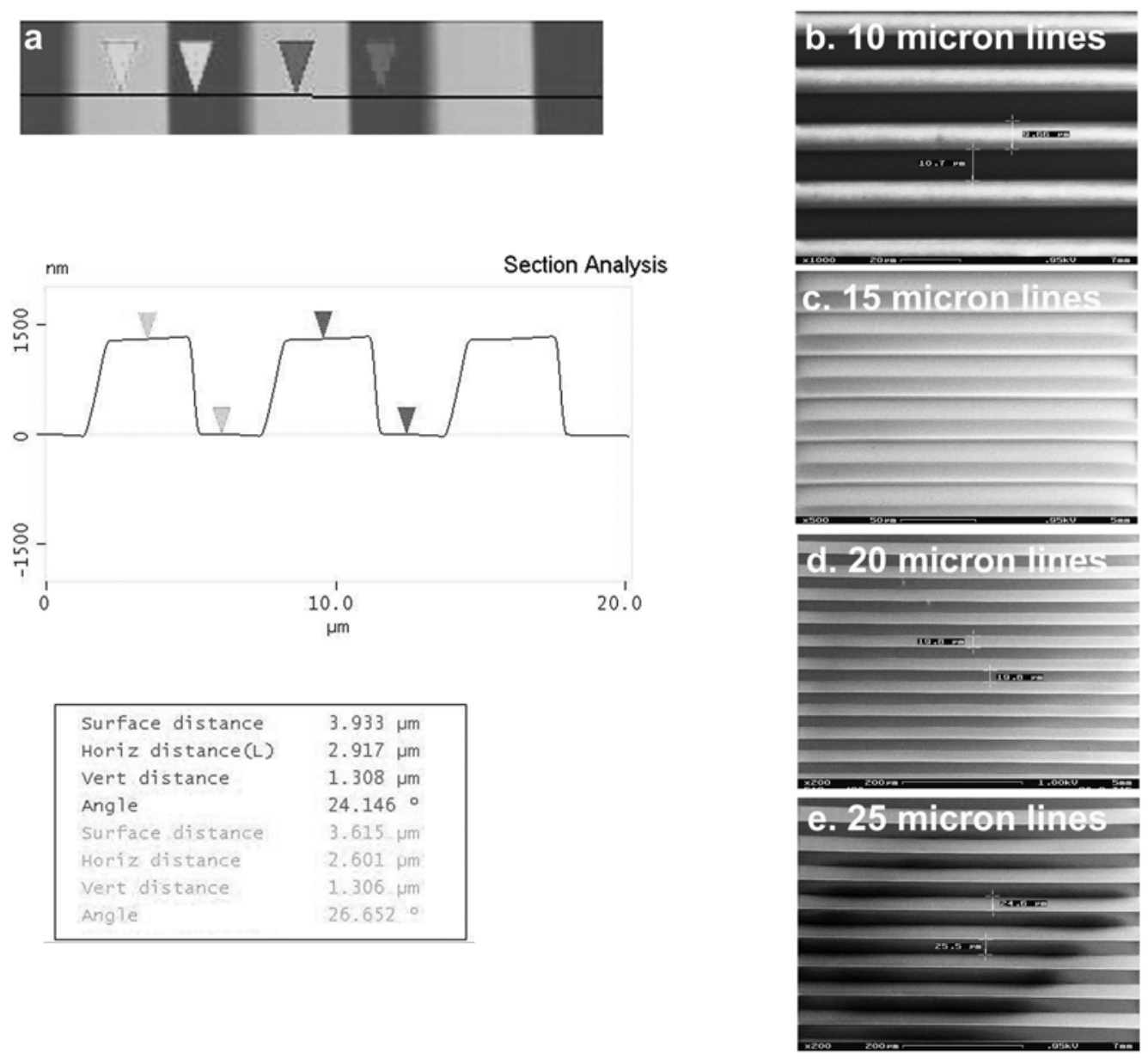

Figure S1. (a) AFM images and cross section analyses showing the height (1.3 micron) of the PDMS stamps used in this work and (b-e) the SEM images of the PR masters of line patterns (10, 15, 20 and 25 micron) used in this study. 


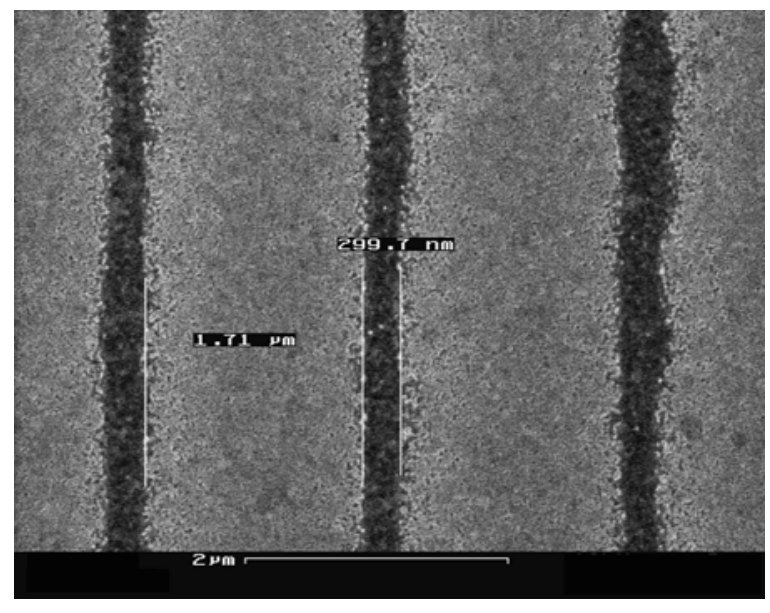

Figure S2. SEM image of submicron-sized trenches on the surface of Au substrate fabricated from $1 \times 1 \mu \mathrm{m}$ line stamps using oCP. The average trench width was $\sim 300 \mathrm{~nm}$. Only single trench per repeating unit has been produced. 
a)
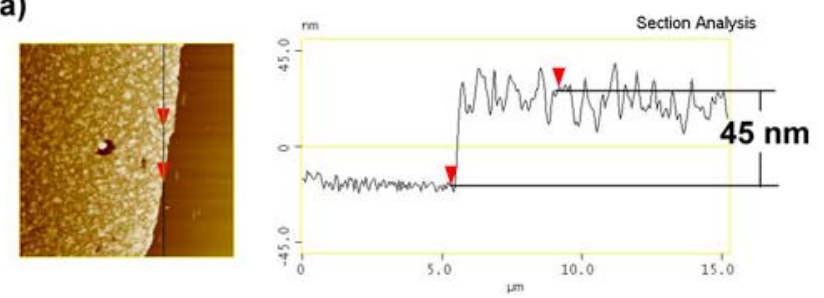

b)
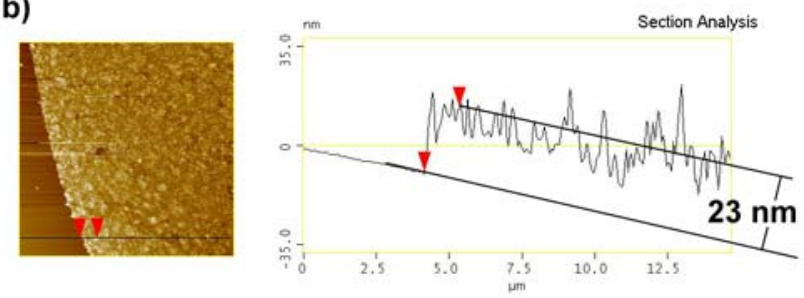

Figure S3. AFM images and their section analyses of six-layered unpatterned LB films of Pt@ $\mathrm{Fe}_{2} \mathrm{O}_{3}$ core-shell nanoparticles (a) before and (b) after solid-state conversion. 